\title{
Fabricação e utilização experimentais de réplicas de tangas marajoara
}

\author{
Igor Rodrigues* \\ André Prous ** \\ Camila Jácome* \\ Luiza Câmpera*
}

\begin{abstract}
RODRIGUES, I.; PROUS, A.; JÁCOME, C.; CÂMPERA, L. Fabricação e utilização experimentais de réplicas de tangas marajoara. R. Museu Arq. Etn., São Paulo, n. 21, p. 265-274, 2011.
\end{abstract}

Resumo: Apresentamos, neste trabalho, uma experimentação que envolveu a fabricação de várias réplicas de tangas marajoaras, assim como sua utilização por mulheres jovens. Debate-se a forma de elaboração desses artefatos, as possíveis modalidades de fixação e a sua " confortabilidade ". Verificou-se qual a posição das peças no corpo, assim como os movimentos possíveis. Foi estudada a variação de posição dos cordões de fixação em função do modelo de tanga e dos movimentos realizados. Os resultados destas observações foram comparados com as marcas de utilização encontradas nas peças arqueológicas. Algumas observações foram também feitas a respeito de elementos da decoração pintada e da situação em relação ao corpo durante a utilização das tangas.

Palavras-chave: Tangas - Fase marajoara - Arqueologia experimental.

\section{Introdução}

m complementação ao levantamento
geral e ao estudo das tangas marajoaras realizado por André Prous desde 2010 (Prous 2011; Prous \& Lima 2011), se produziram cópias de várias tangas e foram realizadas experiências de utilização, visando verificar sua adaptação ao corpo feminino e

$\left({ }^{*}\right)$ Universidade Federal de Minas Gerais.

<igor_mmrodrigues@hotmail.com>; <cpjacome@yahoo.com.br>; <luizacampera@hotmail.com>

$\left({ }^{* *}\right)$ Universidade Federal de Minas Gerais. CNPq; Missão Arqueológica Franco-Brasileira de Minas Gerais. <aprous80@gmail.com> as possibilidades de utilização em atividades diversas, assim como marcas de uso. Como modelo, dispúnhamos das medidas levantadas em peças arqueológicas por B. Meggers e C. Evans (Meggers \& Evans 1957) e por um de nós (A. Prous - catálogo de tangas em preparação). Foram fabricadas 16 réplicas de tangas originais pintadas e uma réplica de tanga cujo original era apenas engobado.

Esta pesquisa foi realizada no Centro Especializado de Arqueologia pré-histórica do Museu de História Natural da UFMG, com o apoio do laboratório de cerâmica da Escola de Belas Artes (onde os artefatos foram queimados) e de cinco estagiárias do curso de graduação em arqueologia da FAFICH-UFMG, que se dispuseram a testar as réplicas. 


\section{Fabricação das tangas}

As tangas foram fabricadas por um dos autores (Igor Rodrigues) deste trabalho que, embora tenha cursado uma matéria de cerâmica na escola de Belas Artes da UFMG, tem pouca experiência em fabricação de objetos em terracota. Foram realizadas 17 réplicas, em três etapas. As nove primeiras tangas foram descartadas por imperfeições. A seguir, duas peças foram feitas usando-se as dimensões médias das peças arqueológicas levantadas; das últimas seis peças, quatro reproduziram as medidas (largura, altura e arqueamento) de tangas arqueológicas reais, representativas das três morfologias encontradas entre as peças arqueológicas definidas por A. Prous (2011). Essas réplicas reproduzem as tangas $n^{\circ} \mathrm{MF} 67$ (forma 2, monocroma), 114 (forma 3), 115 (intermediária entre as formas 1 e 3) e 116 (forma 1) do catálogo de tangas marajoara pintadas atualmente em fase de preparação. As outras duas correspondem à média respectivamente das formas 1 (peça 114B) e 3 (peça no2).

Sendo o nosso objetivo estudar as condições de utilização dessas peças, não nos preocupamos em reproduzir fielmente a composição das pastas ou a forma de queima. Ao utilizar argilas de excelente qualidade, não colocamos antiplástico (cuja presença pode ser observada nas fraturas das peças arqueológicas), nem queimamos as peças em fogueiras abertas - como o foram presumivelmente as tangas originais -; de qualquer forma, tanto as peças arqueológicas quanto as experimentais acabaram apresentando uma mesma queima oxidante.

As nove primeiras tangas experimentais foram fabricadas com uma argila coletada perto do sítio tupiguarani Florestal (baixo Rio Doce-MG), moldando-se as peças sobre uma cabaça. Esta argila, rica em mica e arenosa, mostrou-se pegajosa e difícil de moldar; das peças fabricadas com esta argila seis quebraram durante o alisamento, uma rachou durante a secagem e duas deformaram-se muito durante a queima, tornando-se muito diferente dos modelos.

Assim sendo, passamos a usar uma argila preparada, própria para preparação de telhas e tijolos, disponibilizada pela escola de Belas Artes da UFMG para o curso de cerâmica. Menos pega- josa e mais fácil de trabalhar, foi com ela que se prepararam as tangas efetivamente experimentadas (Fig. 1).

A largura das peças reproduzidas varia de 9,7 a $16,4 \mathrm{~cm}$; a altura entre 9,4 e $10,8 \mathrm{~cm}$, enquanto seu arqueamento vai de 3,4 a $4,2 \mathrm{~cm}$, variando a espessura entre 5 e $7 \mathrm{~mm}$ (Tabela 1 ).

A manufatura começa colocando a argila úmida numa superfície plana, formando-se uma "pizza" de espessura pouco maior que aquela pretendida para a tanga. A forma é recortada com uma faca de madeira e a peça modelada, adelgaçada aos poucos por pressão com um seixo (método que não deu os melhores resultados) ou com a palma da mão (método finalmente preferido) desde o centro para a periferia. Uma vez adquirida a espessura final desejada, as peças são recortadas novamente. Um primeiro alisamento das superfícies e o arredondamento das beiradas são então realizados com os dedos. Realizamos então um arqueamento provisório dessas pré-formas, que foram colocadas sobre uma cabaça ou sobre outra tanga já pronta para secar cerca de 40 minutos na sombra, em ambiente quente de verão (mais de $30^{\circ} \mathrm{C}$ ), até que a argila perca quase completamente sua plasticidade. Mostrando-se a pasta suficientemente firme, se podem ajustar delicadamente as curvaturas (longitudinal e transversal) com o auxílio de um perfilador para que correspondam exatamente ao seu modelo arqueológico. Uma vez conformada a peça e a consistência do objeto chegando no "ponto de couro" (termo utilizado pelos oleiros para expressar o estágio adequado a este tipo de tratamento, $c f$. Mattison 2004), realizamos um alisamento das superficies com um fragmento triangular de cabaça (obtendo uma superfície fosca) e um polimento com seixo roliço (resultando numa superfície brilhante, com facetas discretas marcando a passagem do objeto). Nesta etapa, algumas peças quebraram particularmente nas extremidades, provavelmente quando não se exercia uma contra-força suficiente com os dedos na face oposta ao polimento (Fig. 2). No final deste processo perfuramos as três pontas, pressionando-as com o cálamo de uma pena de fora para dentro da peça, para obter orifícios de cerca de $2 \mathrm{~mm}$ de diâmetro semelhantes àqueles das 

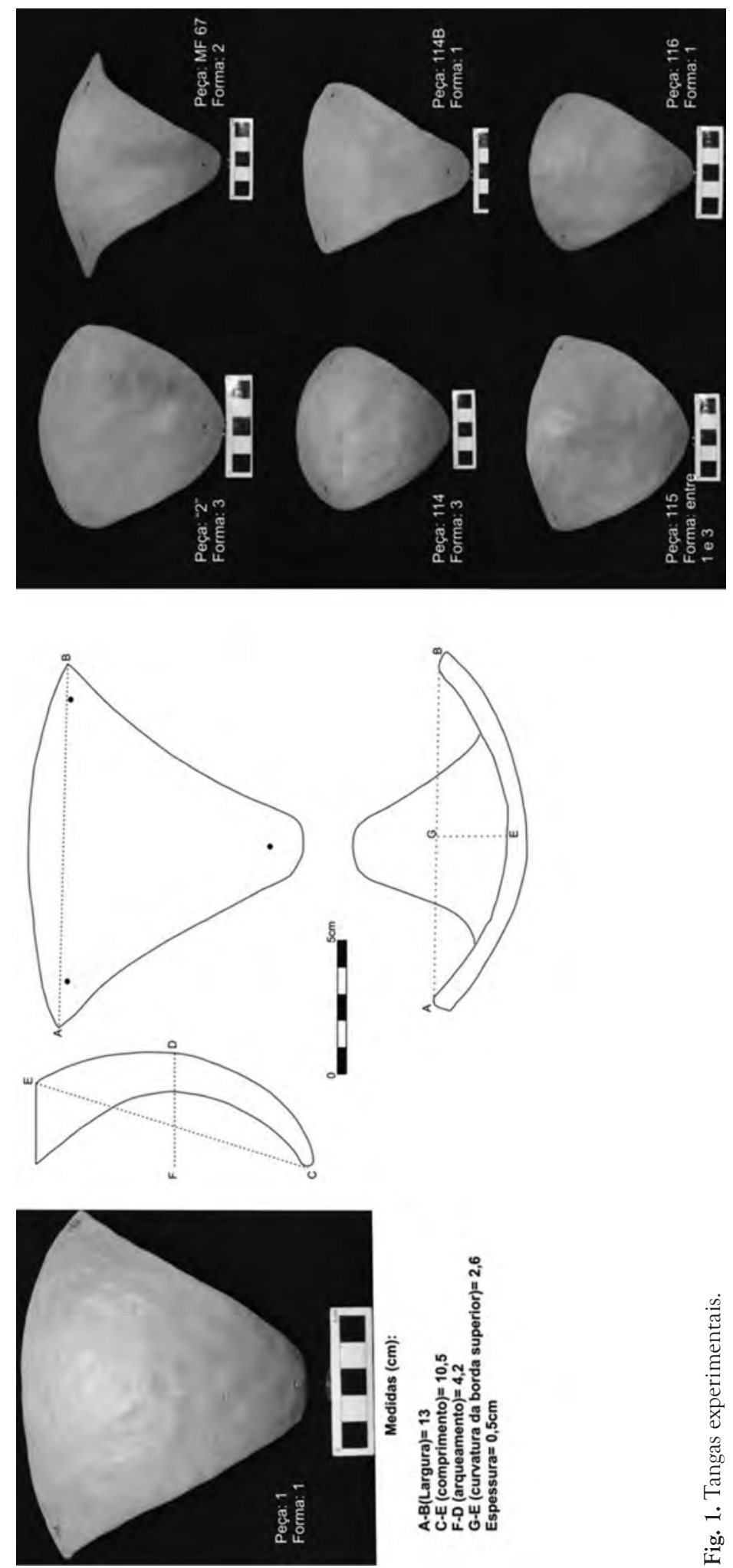

苞 
Tabela 1

\begin{tabular}{ccccc}
\hline \multicolumn{5}{c}{ Medidas das tangas experimentais } \\
\hline \hline \multicolumn{4}{c}{ Medidas (cm) das peças experimentais } \\
\hline $\mathrm{N}^{\circ}$ & Largura & Altura & Arqueamento & Curvatura da borda superior \\
\hline 1 & 13,0 & 10,5 & 4,2 & 2,6 \\
2 & 10,9 & 10 & 3,4 & 1 \\
MF 67 & 16,4 & 10,8 & 3,5 & 2,1 \\
114 & 11,7 & 10,8 & 3,5 & 1 \\
$114 \mathrm{~B}$ & 10,9 & 10,8 & 3,5 & 1,9 \\
115 & 13,5 & 9,9 & 4,0 & 2,6 \\
116 & 9,7 & 9,4 & 3,4 & 2,2 \\
\hline
\end{tabular}

peças originais. A perfuração deve ser realizada numa fase já adiantada de secagem, pois senão forma-se um acúmulo de matéria na saída do orifício, na face interna. Uma última secagem foi realizada na sombra durante dois dias, com as peças colocadas numa superfície plana, sendo já inútil calçar a parte curva. Empilhadas uma acima da outra, foram finalmente queimadas em forno elétrico fechado durante doze horas, numa temperatura de cerca de $980^{\circ} \mathrm{C}$. As peças tiveram uma queima oxidante, ganhando uma coloração laranja. Apresentaram, depois de queimadas, uma pequena retração (entre $0,2 \mathrm{~cm}$ e $1,0 \mathrm{~cm}$, com média de $0,25 \mathrm{~cm}$ ); enquanto a curvatura aumentou em quatro peças, diminuiu em outras duas. Estas modificações, portanto, não alteraram de modo significativo as medidas e as deixaram dentro da margem de variação das peças que serviram de modelo.

É possível que as oleiras marajoaras tenham realizado um retoque por moldagem sobre o corpo da futura usuária antes da secagem final (no mesmo momento em que utilizamos o perfilador); em todo caso, as cópias que realizamos por modelagem manual parecem ter sido bem sucedidas.

\section{Utilização das tangas}

Duas arqueólogas jovens (experimentadoras « $A$ » $\mathrm{e}$ 《 $\mathrm{B}$ ») testaram inicialmente a peça experimental $n^{\circ} 1$; cinco estagiárias ( " $\mathrm{C}$ », « $\mathrm{D}$ ", « $E$ », « $F$ » $e$ " $G$ ») experimentaram as outras seis. Todas têm altura moderada (Tabela 2), embora quatro delas sejam um pouco altas em relação à grande maioria das mulheres indígenas. Apresentaremos sucessivamente o resultado das observações realizadas pelos dois grupos.

\section{Resultados do primeiro teste}

Embora tenham feições corpóreas e alturas diferentes, as experimentadoras « $\mathrm{A}$ » $\mathrm{e}$ 《 $\mathrm{B}$ » apresentam praticamente a mesma medida de quadril. Ambas as pesquisadoras vestiram uma calça de tecido fino e modelagem justa por baixo, sobre a qual fixaram a tanga. Após vá-

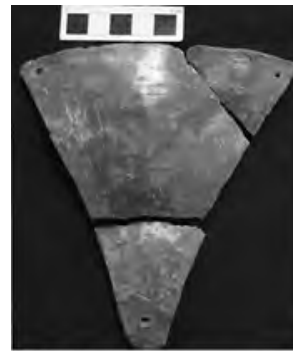

Quebra antes da queima (durante o polimento)

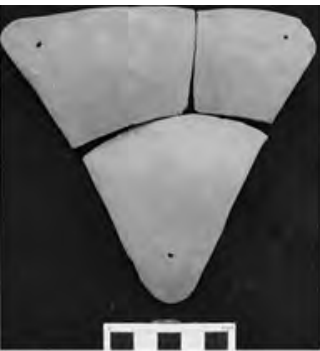

Quebra antes da queima (pressão sobre o corpo)

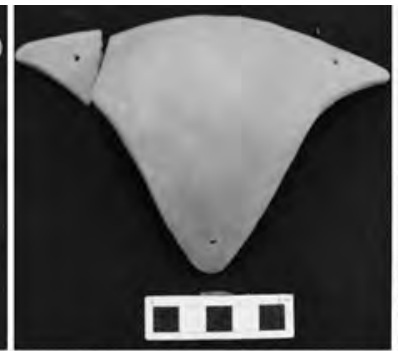

Quebra antes da queima (choque)

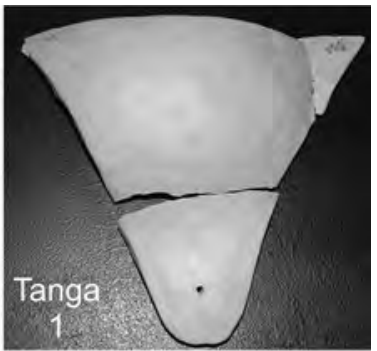

Quebra pós-queima (queda)

Fig 2. Formas de fraturas. 
Tabela 2

\begin{tabular}{|c|c|c|}
\hline \multicolumn{3}{|c|}{ Medidas das experimentadoras } \\
\hline Experimentadora & $\begin{array}{c}\text { Altura } \\
(\mathrm{cm})\end{array}$ & $\begin{array}{c}\text { Quadril } \\
\text { (cm) }\end{array}$ \\
\hline " $A »$ & 1,64 & 99 \\
\hline «B» & 1,57 & 98 \\
\hline « $\mathrm{C} »$ & 1,67 & 96 \\
\hline «D» & 1,60 & 111,5 \\
\hline « $E »$ & 1,62 & 95 \\
\hline "F» & 1,61 & 105 \\
\hline «G» & 1,64 & 95 \\
\hline
\end{tabular}

rias tentativas de fixação, a tanga foi amarrada por três cordões curtos impregnados de resina, cada um deles passando por um dos três furos do objeto; a extremidade dos cordões ficou presa por um simples nó na face interna da peça. Os cordões foram amarrados entre si com um laço na parte de trás do corpo, na linha da cintura, de forma a deixar a peça de cerâmica apertada contra o corpo (Fig. 3); outra possibilidade seria de fixar os cordões superiores perto de uma das extremidades laterais da tanga, para dispensar ajuda. As experimentadoras relataram que a peça não era incômoda: o encaixe provou ser totalmente adaptado anatomicamente. A tanga cobre o monte de Vênus até a metade da vulva, terminando pouco abaixo da abertura da uretra; deixa, portanto, descoberto o canal vaginal. As pesquisadoras testaram várias posições: de cócoras, sentadas no chão de
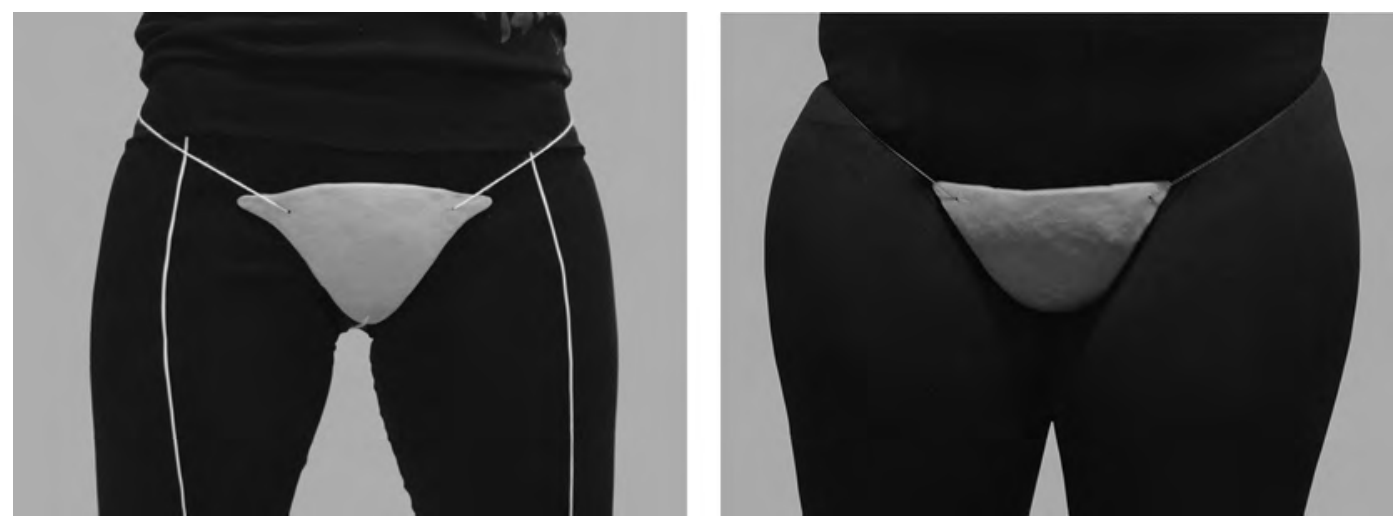

pernas esticadas, sentadas num banco. Ficaram de repouso, andaram, dançaram etc. A tanga mostrou não incomodar na movimentação e nenhuma posição criou risco de quebrá-la, pois o artefato nunca entrou em contato com o chão ou com o banco (este baixo, como aqueles conhecidos da fase Marajoara). Durante todas as atividades foi registrada a posição dos cordões em relação à horizontal. Para tanto, considerou-se como linha de referência aquela que reúne os dois furos superiores (Fig. 4), que marcaria a horizontal durante a utilização. $\mathrm{O}$ desvio em relação a esta linha foi medido em graus. Verificou-se que a posição do cordão oscilava dentro de um estreito leque - menor no caso da experimentadora " $\mathrm{B}$ " (oscilação de $26^{\circ}$ ) - e mais aberto no caso de « $\mathrm{A}$ » $\left(39^{\circ}\right)$, em função da movimentação (Fig. 4 e Tabela 3). De qualquer forma, não chegou a haver uma marca de utilização impressa na espessura da tanga, o que iria requerer um tempo de utilização bem superior àquele desta primeira experiência.

Oangulo mostrou-se maior quando se está em pé ou agachada de cócoras, e menor na posição sentada no chão de pernas esticadas. Ôngulo é intermediário quando se senta em um banquinho. Houve uma grande diferença de resultado entre as duas experimentadoras na posição sentada em banco baixo e em pé; talvez isto reflita a impressão de melhor adaptação anatômica sentida por uma delas enquanto a outra percebia uma adequação levemente menor ao seu corpo.

Fig. 3. Moças experimentando as tangas. 


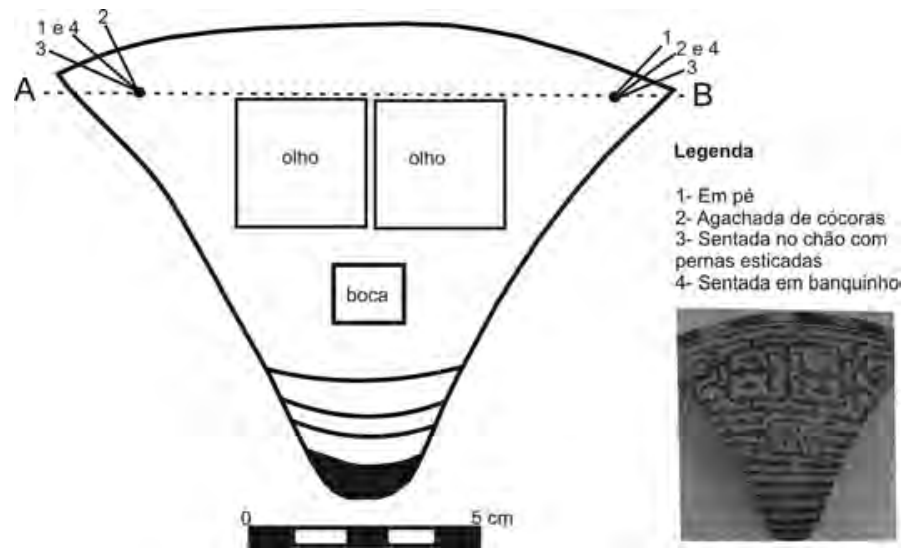

Fig. 4: Ângulo dos cordões de acordo com a posição do usuário. posição em pé quanto sentada. Segundo as experimentadoras « $C$ » « $E$ », a altura desta peça foi também considerada insuficiente, incomodando a parte inferior. Apenas uma experimentadora ( $\mathrm{D}$ ») aprovou totalmente esta tanga, frisando que parecia ter sido modelada para ela; isto, aparentemente, porque apresenta a maior largura de quadril. A peça MF 67 (forma 2, cópia de peça engobada de vermelho) se adaptou com perfeição à anatomia das experimentadoras « $\mathrm{C}$ » $\mathrm{e}$ " $\mathrm{E}$ » (de quadril mais
Nota-se que praticamente todas as tangas marajoaras pintadas são decoradas com um rosto (Prous 2007, 2011; Prous \& Lima 2011). Uma figura quadrangular (retângulo ou losango) - graficamente central, representa a boca, mas não está situada no centro geométrico da tanga. As pesquisadoras notaram que sua posição durante a utilização da tanga corresponde ao clitóris, o que, provavelmente, não seja uma coincidência (Fig. 4).

\section{Resultados do segundo teste}

Este foi realizado pelas cinco experimentadoras « $C$ », « $D$ », « $E$ », « $F$ » $e$ " $G$ ». Cada uma delas testou as mesmas seis diversas tangas e, portanto, as três formas. Os cordões de amarração, desta vez, foram de algodão, com um pouco menos de $2 \mathrm{~mm}$ de diâmetro (para passar pelos orifícios). A peça $n^{\circ} 2$ (representante da forma 3) incomodou quase todas elas, pela falta de cava lateral; o incômodo foi percebido tanto na estreito) e foi muito bem aceita pelas « $F$ » e « $G$ » (quadris respectivamente mediano e estreito). Apenas não se adaptou bem ao corpo de « $\mathrm{D}$ » (como vimos, de quadril mais largo), pois a curvatura transversal da tanga não se adaptava à forma do corpo. A peça 114 (forma 3) incomodou quatro das cinco mulheres. Para três delas, o problema foi no encaixe das partes laterais (ausência de cava); outra teve problemas com a parte inferior (por causa da curvatura forte). Apenas uma das moças ( $G$ ") se sentiu a vontade com esta peça - embora não tendo a impressão de se tratar de uma tanga "feita para ela”. A parte inferior da cópia da tanga 114B foi muito incômoda para « $C$ » $e$ « $D$ » em razão da curvatura muito acentuada; o encaixe foi melhor para " $E$ » e « $G$ »; em compensação, « $F$ » se sentiu perfeitamente bem nela. As cópias de 115 e 116 não agradaram a ninguém: a falta de cava (na tanga 115), sobretudo, incomodou « $F$ " e « $G$ »; « $E$ » reclamou de incômodo na virilha, enquanto « $\mathrm{D}$ » achou que a peça restringia sua

Tabela 3

Medidas dos ângulos entre o cordão e a horizontal (peça 1)

\begin{tabular}{ccccc} 
Expe. & $\begin{array}{c}\text { Ângulo - na } \\
\text { posição em pé }\end{array}$ & $\begin{array}{c}\text { Ângulo - na } \\
\text { posição de cócoras }\end{array}$ & $\begin{array}{c}\text { Ângulo - no chão, } \\
\text { pernas esticadas }\end{array}$ & $\begin{array}{c}\text { Ângulo - sentado } \\
\text { num banco baixo }\end{array}$ \\
"A " & 41 & 63 & 24 & 41 \\
«B " & 47 & 37 & 21 & 37 \\
\hline
\end{tabular}


movimentação. Finalmente, a tanga 116 foi considerada pequena por quatro pessoas (sendo « $\mathrm{D}$ » a exceção) e todas reclamaram do seu arqueamento - exagerado em relação ao tamanho.

Sintetizando, verificamos que a peça $\mathrm{n}^{\circ} 2$ (forma 3) se encaixou perfeitamente na experimentadora « $\mathrm{D}$ » (de maior quadril); a cópia de MF 67 (tanga monocroma de forma 2) parecia ter sido feita para « $\mathrm{C}$ » $\mathrm{e}$ " $\mathrm{E}$ " (os menores quadris). « $G$ » não ficou totalmente satisfeita com nenhuma tanga, embora considere alguns modelos (114 e MF 67) aceitáveis.

Enquanto a tanga 116 poderia ser destinada a alguém menor, a tanga 115 poderia ter sido adequada a uma pessoa mais corpulenta.

Deste modo, podemos pensar que as várias formas foram feitas para padrões corporais específicos, sendo talvez moldadas, na fase final de manufatura, no corpo das futuras usuárias.

Todas as experimentadoras confirmaram a observação anterior: a localização do desenho de boca corresponde à posição do clitóris - a não ser no caso da peça menor (116).

Verificou-se que os finos cordões de algodão eram muito frágeis; certamente, utilizaram-se fibras mais resistentes na pré-história - inclusive, as marcas de utilização arqueológicas devem ter sido causadas por matérias ricas em fitólitos - talvez de palmeira. De qualquer forma, observou-se que o cordão inferior de fixação sempre se encostava à face externa das tangas, independentemente da forma, criando uma linha de fricção. Isto se deve à maior curvatura da peça neste local e ao fato de que o cordão sobe para poder se reunir aos demais, logo acima da cintura. O contato dos cordões superiores com a face externa das extremidades laterais variou muito em função de cada experimentadora e de cada artefato. Na peça no 2, quando usada por « C », o cordão estava completamente encostado à parede (em condição, portanto, de criar uma canaleta comprida de desgaste); quando usada por « E ", o contato era limitado (poderia provocar apenas um desgaste curto), ao passo que, com « F " e " $G$ ", o cordão afastou-se imediatamente da peça. Estes três graus de contato estão em conformidade com o que se observa nas tangas arqueológicas (Prous
\& Lima 2011). A mesma discrepância entre as usuárias se notou para todas as demais peças, com exceção do número 114B, na qual os cordões ficaram todos em contato com a superfície até a extremidade da peça, sem que tenhamos ainda esclarecido as razões desta particularidade. Apesar do pouco tempo de teste e da pouca capacidade abrasadora do algodão, chegou-se a observar um esboço de desgaste nas duas tangas que foram utilizadas mais tempo.

Uma das questões que queríamos esclarecer era a razão pela qual o desgaste externo nas peças arqueológicas - com apenas duas exceções - se apresenta na forma de uma canaleta linear, e não em forma de leque, sugerindo que o movimento do cordão fosse linear longitudinal (agindo como um serrote), e não linear transversal (atuando por raspagem a partir do orifício). Isto parece decorrer do fato de que quando as tangas estão bem amarradas e adaptadas ao corpo, o ângulo do cordão não varia durante o andar. Desta forma, se esta fosse a movimentação mais comum durante a utilização das peças, a tensão poderia ser linear, com um leve movimento de serra consecutivo ao giro das cadeiras. $\mathrm{O}$ mesmo movimento de "serra" ocorre ao se amarrar a tanga bem rente ao corpo, o que melhora sua confortabilidade (Tabelas 4 e 5).

As tabelas 4 e 5 mostram que com estas cinco experimentadoras, a variação de angulação do cordão em função das posições foi muito menor que no primeiro teste - provavelmente porque se usaram réplicas mais próximas de originais e que, aproveitando-se a experiência adquirida, apertaram-se mais as peças no corpo. Por outro lado, há variações individuais, embora se note que, de forma geral, o ângulo com a horizontal tenda a ser maior quando a pessoa está em pé. Algumas experimentadoras utilizaram a tanga durante um dia inteiro. Uma delas, usando a peça 114B, tomou inclusive conta de uma criancinha de colo, limpou a casa etc., não sentindo nenhum incômodo durante qualquer desses afazeres - a não ser, no final do dia de trabalho, uma leve irritação em razão do atrito da cerâmica em contato direto com a pele. 
Tabela 4

\begin{tabular}{|c|c|c|c|c|c|c|c|c|c|c|c|c|}
\hline \multicolumn{13}{|c|}{ Medidas dos ângulos entre o cordão e o eixo horizontal (peças 2, MF67 e 114) } \\
\hline \multirow{2}{*}{ Expe. } & \multicolumn{4}{|c|}{ Tanga 2} & \multicolumn{4}{|c|}{ Tanga MF 67} & \multicolumn{4}{|c|}{ Tanga 114} \\
\hline & Em pé & Cócoras & Chão & Banco & Em pé & Cócoras & Chão & Banco & Em pé & Cócoras & Chão & Banco \\
\hline «C & 17 & 17 & 17 & 17 & 24 & 13 & 24 & 13 & 23 & 23 & 23 & 23 \\
\hline « D » & 13 & 13 & 13 & 13 & 17 & 17 & 17 & 17 & 22 & 22 & 22 & 22 \\
\hline «E» & 20 & 20 & 20 & 38 & 18 & 18 & 18 & 18 & 24 & 24 & 24 & 24 \\
\hline «F » & 18 & 18 & 18 & 18 & 19 & 19 & 19 & 19 & 11 & 11 & 11 & 18 \\
\hline " $G$ » & 7 & 7 & 7 & 7 & 13 & 13 & 13 & 13 & 11 & 11 & 11 & 18 \\
\hline
\end{tabular}

Tabela 5

\begin{tabular}{|c|c|c|c|c|c|c|c|c|c|c|c|c|}
\hline \multicolumn{13}{|c|}{ Medidas dos ângulos entre o cordão e o eixo horizontal (peças 114B, 115 e 116) } \\
\hline \multirow[b]{2}{*}{ Expe. } & \multicolumn{4}{|c|}{ Tanga 114B } & \multicolumn{4}{|c|}{ Tanga 115} & \multicolumn{4}{|c|}{ Tanga 116} \\
\hline & Em pé & Cócoras & Chão & Banco & Em pé & Cócoras & Chão & Banco & Em pé & Cócoras & Chão & Banco \\
\hline « $\mathrm{D}$ » & 14 & 14 & 14 & 14 & 22 & 22 & 22 & 5 & 17 & 6 & 6 & 6 \\
\hline «E» & 17 & 17 & 28 & 17 & 29 & 29 & 29 & 29 & 15 & 15 & 15 & 15 \\
\hline «F» & 7 & 7 & 7 & 18 & 21 & 21 & 21 & 21 & 19 & 19 & 19 & 19 \\
\hline « $G$ » & 8 & 8 & 8 & 23 & 5 & 17 & 17 & 17 & 13 & 13 & 13 & 13 \\
\hline
\end{tabular}

\section{Conclusões e limites da pesquisa}

A fabricação das tangas mostrou ser um processo simples, que pode ser realizado por um(a) oleiro(a) inexperiente. Uma experiência não controlada de fabricação de uma tanga, queimada em fogueira aberta anos atrás no Museu de História Natural, já tinha evidenciado que este tipo de peça era facilmente produzido. Longe de exigir um artesão especializado, poderia a rigor ser fabricada pelas próprias usuárias. De fato, algumas peças arqueológicas mostram certa inabilidade do seu autor.

Estamos cientes de que estes primeiros testes de utilização padecem de várias limitações. Em primeiro lugar, não dispúnhamos de experimentadores indígenas. Ora, há pouca chance de que os corpos femininos da população universitária do Brasil central apresentem as proporções "clássicas" das antigas mulheres marajoaras. Mesmo assim, a boa adaptação das peças experimentais aos modelos que se dispuseram a testá-las parece validar a nossa tentativa.

Outra limitação é devida à pouca duração dos experimentos - no entanto suficiente para mostrar que a utilização da peça não parece excluir nenhuma atividade cotidiana. Apenas um imprevisto (choque, queda) provocaria uma quebra. De fato, ocorreram acidentes, apenas no momento de amarrar as peças, quando várias experimentadoras deixaram cair a peça que se quebrou - evidenciando as mesmas formas de fragmentação encontrados em tangas quebradas pré-históricas. Faltou ainda realizar testes com crianças de ambos os sexos - uma operação eticamente problemática. Seria teoricamente possível utilizar réplicas de bacias de corpos infantis, conservados na Faculdade de Medicina da UFMG para avaliar as possibilidades de adaptação das tangas a corpos mais jovens e verificar quais partes poderiam ser cobertas além do monte de Vênus, dependendo da idade dos usuários. Talvez a tanga 116 esteja, inclusive, adaptada a um corpo imaturo. Seria também interessante testar corpos de mulheres corpulentas. Uma moça grávida (no $8^{\circ}$ mês de gestação) testou as três formas de tanga e não sentiu nenhum incômodo.

A nossa impressão é de que a morfologia das tangas é menos importante do que as suas 
medidas, na adaptação ao corpo das experimentadoras; em compensação, o grau de curvatura é, sem dúvida, muito importante - explicando provavelmente a variação muito reduzida de arqueamento entre as tangas arqueológicas.

Para completar a pesquisa, um teste foi realizado com dois colaboradores homens do Centro de Pesquisa do MHN-UFMG; infelizmente, estes são bem mais altos ( $1,75 \mathrm{~m}$ e 1,80 $\mathrm{m})$ que os indígenas comuns, de forma que suas conclusões não podem ser consideradas definitivas. As tangas de formas 1 e 2 se mostraram impraticáveis, por não cobrirem completamente a genitália. A forma 3 chega a cobrir o suficiente, embora tenha criado um grande incômodo para os experimentadores ; segundo eles, ainda, seria impraticável uma amarração eficiente da peça ao corpo. Pode-se indagar, no entanto, se indivíduos masculinos pré-adolescentes poderiam utilizar este tipo de peça.

A posição dos cordões durante a utilização corresponde às marcas de desgaste observadas nas faces externas das peças originais; ainda pretendemos estudar a angulação destas marcas nas peças arqueológicas catalogadas, para verificar se a angulação das canaletas é mais compatível com a movimentação em pé ou com outra po- sição - sentada, por exemplo. Não se examinou ainda o desgaste interno provocado pelos nós nas réplicas.

Evidentemente, a experimentação que apresentamos não permite afirmar quais possíveis grupos de gênero, idade e status social (Schaan 2003), utilizaram efetivamente tangas, pois cada uma das três formas apresenta tanto exemplares arqueológicos monocromos (vermelho) quanto pintados sobre engobo branco. Levantamos, no entanto, algumas pistas novas que pretendemos seguir no futuro, com o auxílio do curso de moda e da Escola de Medicina da UFMG.

\section{Agradecimentos}

Nossos agradecimentos vão ao Professor João Cristelli e a Adriano Zampelini, ambos da Escola de Belas Artes da UFMG, que nos forneceram argila para cerâmica e permitiram que usássemos o forno da Escola. Agradecemos particularmente a Ana Lídia Nézio, Deise Carvalho, Flávia Vieira, Mara Chanoca, Raquel Nolasco e Sarah Schimi$\mathrm{dt}$, que aceitaram testar e usar as tangas, assim como Luís Felipe Alves. A pesquisa foi financiada com um grant do CNPq.

RODRIGUES, I.; PROUS, A.; JÁCOME, C.; CÂMPERA, L. Reproduction and use of archaeological pubic covers from Marajoara Phase, Brazil. R. Museu Arq. Etn., São Paulo, n. 21, p. 265-274, 2011.

Abstract: We have made 17 reproductions of ceramic prehistoric pubic covers (tangas) known from Marajo Island. The main purpose was to know how these artifacts were produced, how they were used, and if they reduce mobility or comfort. Some young girls and two men wore these tangas in different ways; the various positions of the strings have been registered and a comparison with prehistoric use marks has been made. Some considerations are also made on the localization of painted elements and their correlation with body parts.

Keywords: Pubic covers - Marajoara phase - Experimental archaeology. 


\section{Referências bibliográficas}

MATTISON, S.

2004 Guia Completo del ceramista - herramientas, materiales y técnicas. Barcelona: Editora Blume.

MEGGERS, B.; EVANS, C.

1957 Archeology at the Mouth of the Amazon. Washington, DC.: Smithsonian Institution, Bureau of American Ethnology, 167.

PROUS, A.

2007 Arte pré-histórica brasileira. Belo Horizonte : C/Arte ed.

2011 A decoração das Tangas Marajoara. Co- municação apresentada ao XVI Congresso Mundial da UISPP e XVI Congresso da $\mathrm{SAB}$, Florianópolis.

PROUS, A.; LIMA, A.

2011 De Cobras e Lagartos - as tangas marajoaras. Revista do Museu de Arqueologia e Etnologia, 21: 231-263.

SCHAAN, D.P.

2003 A ceramista, seu pote e sua tanga: identidade e papéis sociais em um cacicado marajoara. Revista de Arqueologia, 16: $31-45$.

Recebido para publicação em 30 de dezembro de 2011. 